\title{
8
}

\section{impar partilm}

\section{Proteção jurisdicional efetiva na União Europeia: evolução e perspetivas (ou expetativas) futuras}

\author{
Autor(es): $\quad$ Proença, Carlos
}

Publicado por: Centro de Informação Europe Direct de Aveiro; Centro de Estudos

URL

persistente:

URI:http://hdl.handle.net/10316.2/39894

DOI:

DOI:https://doi.org/10.14195/1647-6336_15_4

Accessed : $\quad$ 26-Apr-2023 13:44:22

A navegação consulta e descarregamento dos títulos inseridos nas Bibliotecas Digitais UC Digitalis, UC Pombalina e UC Impactum, pressupõem a aceitação plena e sem reservas dos Termos e Condições de Uso destas Bibliotecas Digitais, disponíveis em https://digitalis.uc.pt/pt-pt/termos.

Conforme exposto nos referidos Termos e Condições de Uso, o descarregamento de títulos de acesso restrito requer uma licença válida de autorização devendo o utilizador aceder ao(s) documento(s) a partir de um endereço de IP da instituição detentora da supramencionada licença.

Ao utilizador é apenas permitido o descarregamento para uso pessoal, pelo que o emprego do(s) título(s) descarregado(s) para outro fim, designadamente comercial, carece de autorização do respetivo autor ou editor da obra.

Na medida em que todas as obras da UC Digitalis se encontram protegidas pelo Código do Direito de Autor e Direitos Conexos e demais legislação aplicável, toda a cópia, parcial ou total, deste documento, nos casos em que é legalmente admitida, deverá conter ou fazer-se acompanhar por este aviso.

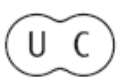




\section{DEBATER \\ A EUROPA}

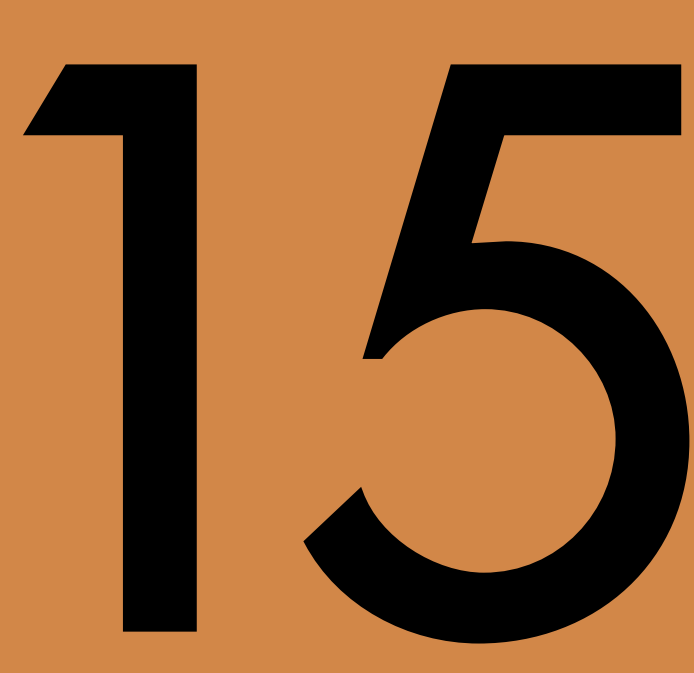

jul-dez 2016

PORTUGAL E A EUROPA.

30 ANOS DE INTEGRAÇÃO

PORTUGAL AND EUROPE.

30 YEARS OF INTEGRATION 


\title{
Proteção jurisdicional efetiva na União Europeia: evolução e perspetivas (ou expetativas) futuras
}

\author{
Carlos Proença \\ Professor, ISCAL \\ E-mail: carlosproenca@sapo.pt
}

\section{Resumo}

$\mathrm{Na}$ evolução do sistema de proteção jurisdicional da União Europeia assinala-se a atribuição de força jurídica à Carta dos Direitos Fundamentais e a previsão da adesão da União à Convenção Europeia dos Direitos Humanos, alterações introduzidas pelo Tratado de Lisboa, com o qual também avulta a eventualidade de condenação dos Estados membros em sanções pecuniárias na mesma ação por incumprimento e a possibilidade de as pessoas físicas ou coletivas interporem recursos de anulação contra atos regulamentares. Se ao Tratado de Lisboa se deve ainda a consagração do direito à tutela jurisdicional efetiva, perdeu-se, contudo, outra oportunidade para se reconhecer ao Provedor de Justiça da União legitimidade para impugnar atos legislativos; ao mesmo tempo, apraz-nos-ia uma inversão da jurisprudência Foto-frost, que negou aos tribunais nacionais a prerrogativa de julgar inválidas disposições europeias.

Palavras-chave: Tratado de Lisboa; direitos fundamentais; ação por incumprimento; recurso de anulação

\begin{abstract}
In its evolution, the European Union's judicial protection system has attributed legal force to the Charter of Fundamental Rights and is considering the prospective accession of the Union to the European Convention of Human Rights. These and other changes such as the possibility of convicting Member States in financial penalties in the same proceeding for failure to fulfil an obligation, as well as the possibility for individuals or institutions to bring action for annulment of regulatory acts - were introduced by the
\end{abstract}


Treaty of Lisbon. However, as it consecrated the right to effective judicial protection, this Treaty missed yet another opportunity of granting to the Ombudsman of the European Union the legitimacy to challenge legislative acts; at the same time, we would like to be given a chance to achieve a reversal in the Foto-frost jurisprudence, which denied to domestic jurisdictional bodies the prerogative to invalidate European provisions.

Key-Words: Treaty of Lisbon; fundamental rights; proceeding for failure to fulfil an obligation; action for annulment

\section{Introdução}

Qualquer sistema de proteção de direitos subjetivos e interesses legítimos convoca duas vertentes que se completam e correspondem às duas faces de uma mesma moeda: uma de natureza proclamatória, de consagração de direitos; outra de cariz garantístico, onde avulta o controlo do seu respeito. Na primeira realçam-se os direitos e interesses que devem ser assegurados pelos poderes públicos, principalmente pelo poder legislativo e pelo poder executivo, bem como pelas atuações dos demais entes jurídicos; na segunda destaca-se a fiscalização do cumprimento de tais pretensões, a cargo dos órgãos inseridos no poder judicial.

Também o modelo de salvaguarda jurisdicional de pretensões de natureza subjetiva (maxime de direitos fundamentais) existente na União Europeia (adiante UE) não prescinde, a montante, da positivação de direitos e interesses; igualmente, a jusante advirá a dimensão de fiscalização da observância destes. Por outras palavras, se é certo que a defesa dos direitos subjetivos e dos interesses legítimos previstos no ordenamento europeu apenas é alcançável se a sua consagração for acompanhada de instrumentos processuais que permitam aos interessados fazerem-se valer dos mesmos em juízo, não menos verdade é que a proclamação das aludidas pretensões também desempenha, inclusivamente num plano ex ante, um papel decisivo no referido modelo. Assim se exige numa UE que se afirma como União de direito, isto é, que se revê no princípio do Estado de direito, comum aos Estados membros e a qualquer país europeu que aspire a aderir à União.

Com o Tratado de Lisboa os Estados membros ofereceram importantes contributos à temática da tutela jurisdicional efetiva na UE. Na dimensão proclamatória avulta a atribuição de eficácia jurídica vinculativa à Carta dos Direitos Fundamentais 
da União Europeia (doravante CDFUE), bem como a introdução de uma base jurídica que autoriza a adesão da União à Convenção Europeia dos Direitos Humanos (a seguir CEDH). Na vertente garantística desataca-se a eventualidade de, no domínio do não cumprimento da obrigação de comunicação das medidas de transposição de diretivas adotadas de acordo com um processo legislativo, os Estados membros poderem ser condenados em sanções pecuniárias no quadro da designada primeira ação por incumprimento, bem assim a reformulação do quarto parágrafo do artigo $263 .^{\circ}$ do Tratado sobre o Funcionamento da União Europeia (TFUE) facilitando a impugnação, pelas pessoas singulares ou coletivas, dos chamados atos regulamentares.

Apesar de ao Tratado de Lisboa se dever ainda a consagração, nos Tratados e pela primeira vez de forma expressa, do direito à tutela jurisdicional efetiva, o mesmo não deixará de representar (mais) uma ocasião perdida para a atribuição ao Provedor de Justiça Europeu da legitimidade processual que o autorize a instaurar, em representação dos cidadãos da União, recursos de anulação contra atos legislativos aprovados pelas instituições europeias. Ademais, o reconhecimento aos órgãos jurisdicionais nacionais de um verdadeiro estatuto de tribunais comuns do ordenamento da UE reclama que lhes seja reconhecida a prerrogativa de julgarem inválidas disposições europeias, ainda que dentro de certos requisitos.

\section{O reforço do imperativo de respeito pelos direitos fundamentais na União} Europeia

O renovado quadro jurídico-institucional europeu, introduzido a partir de 1 de dezembro de 2009 com a entrada em vigor do Tratado de Lisboa, permitiu o reforço do princípio da proteção jurisdicional efetiva na União, antes de mais, na primeira dimensão a que atrás aludimos, ou seja, na positivação de direitos. Tal é visível a dois níveis: de um lado, através da atribuição de valor jurídico obrigatório à CDFUE; de outro, mediante a previsão da adesão da União à CEDH.

\subsection{A vinculatividade da Carta dos Direitos Fundamentais da União Europeia}

Apesar de se destinar a completar o modelo de tutela dos direitos fundamentais existente na União, a CDFUE foi proclamada, em dezembro de 2000, como "mera" 
declaração política de direitos ${ }^{1}$. Ainda que, desde cedo, o Tribunal de Justiça (adiante TJ) e o Tribunal Geral (doravante TG) a tivessem invocado como parâmetro de controlo da atividade normativa das instituições europeias e critério orientador da sua atividade hermenêutica, densificando o n. 3 do artigo 6. ${ }^{\circ}$ do Tratado da União Europeia (TUE) ${ }^{2}$, avultava a falta de força jurídica vinculante do cardápio de direitos e liberdades fundamentais da União.

Com o Tratado de Lisboa, os Estados membros colmataram essa insuficiência ao atribuírem à referida Carta eficácia vinculativa ${ }^{3}$. Na verdade, na norma remissiva constante do n. ${ }^{\circ} 1$ do artigo $6 .^{\circ}$ do TUE atribui-se à CDFUE “o mesmo valor jurídico que os Tratados", dessa forma proclamando-se positivamente direitos fundamentais que os órgãos jurisdicionais da UE, encarados na sua aceção ampla, devem aplicar ${ }^{4}$.

Isto sem embargo dos opting outs negociados pelo Reino Unido e pela Polónia ${ }^{5}$, o que espelha uma via pouco ortodoxa de numa UE composta por 28 Estados membros se caminhar a duas velocidades num domínio nuclear como o da salvaguarda dos direitos fundamentais; a República Checa viu ser-lhe reconhecido um estatuto especial face à Carta, que a aproxima da posição daqueles dois Estados membros.

Tal significa que, no atual quadro, tanto o Tribunal de Justiça da União Europeia (TJUE) como os órgãos jurisdicionais nacionais, ressalvados os tribunais dos três Estados membros que permanecem à margem da Carta de Direitos Fundamentais com efeitos jurídicos imperativos, estão obrigados a aplicá-la e a sindicar o seu respeito sobretudo no âmbito das atuações dos poderes públicos, mas também dos entes privados na parte em que a CDFUE os vincule. Para o Reino Unido, para a Polónia e para a

\footnotetext{
${ }^{1}$ Cfr. Koen LENAERTS, Fundamental rights to be included in a Community Catalogue, in European Law Review, 1991 (Vol. 16; n. ${ }^{\circ}$ 5), págs. 367 e segs; Fundamental rights in the European Union, in European Law Review, 2000 (Vol. 25; n. ${ }^{\circ}$ 6), pág. 599.

${ }^{2}$ O TJ fê-lo, entre muitos outros, nos acórdãos Unibet, de 13 de março de 2007, processo C-432/05, Col. 2007, págs. I-2301 e segs; Kadi e o. vs. Conselho e Comissão, de 3 de setembro de 2008, processos apensos C-402/05 P e C-415/05 P, Col. 2008, págs. I-6351 e segs. O TG fê-lo, designadamente, nos arestos proferidos nos casos Jégo-Quéré vs. Comissão, de 3 de maio de 2002, processo T-177/01, Col. 2002, págs. II-2365 e segs; e Philip Morris e o. vs. Comissão, de 15 de janeiro de 2003, processos apensos T-377/00, T-379/00, T-380/00, T-260/01 e T-272/01, Col. 2003, págs. II-1 e segs.

${ }^{3}$ Matéria tratada também na Declaração n. ${ }^{\circ} 1$ anexa ao Tratado de Lisboa, relativa à CDFUE. Cfr. Carlos CARRANHO PROENÇA, Tutela jurisdicional efetiva no direito da União Europeia. Dimensões teoréticas e práticas, Coimbra, 2016, págs. 303, 304, 307 e 308.

${ }^{4}$ A Carta permitiu a evolução, na UE, de um sistema de proteção de direitos fundamentais pretoriano e autorregulador para um modelo de proclamação positiva dos aludidos direitos, no qual os órgãos integrados no TJUE passaram a participar como aplicadores e não já, diferentemente do que sucedera até à aprovação daquela, como criadores de direitos fundamentais.

${ }_{5}^{5}$ Cfr. Protocolo n. ${ }^{\circ} 30$ anexo ao TUE, ao TFUE e ao Tratado da Comunidade Europeia da Energia Atómica.
} 
República Checa a Carta mantém-se como declaração política de direitos, desprovida de efeitos jurídicos vinculativos.

Ainda assim, os Estados membros tiveram a prudência de não inserir a CDFUE no articulado dos Tratados, o que preveniu analogias precipitadas entre estes e as Constituições nacionais, bem como o reacendimento do espetro do federalismo europeu $^{6}$.

A Carta consagra, desde a sua aprovação em 2000, expressamente, entre outros, o direito à tutela jurisdicional efetiva (vide n. ${ }^{\circ} 1$ do artigo 47. ${ }^{\circ}{ }^{7}$, antecipando-se aos próprios Tratados na proclamação de um direito fundamental dos particulares ante a administração pública europeia, o qual se afigura estruturante de uma UE que se afirma como União de direito (artigo $2 .^{\circ}$ do TUE) ${ }^{8}$.

\subsection{A adesão da União à Convenção Europeia dos Direitos Humanos}

Igualmente no aspeto proclamatório da proteção dos direitos subjetivos e dos interesses legítimos, a entrada em vigor do Tratado de Maastricht positivou o reconhecimento e a garantia, pela União, dos direitos fundamentais previstos na Convenção Europeia de Salvaguarda dos Direitos do Homem e das Liberdades Fundamentais, a qual contempla um standard mínimo de tutela de direitos partilhado por 47 países europeus, entre eles os Estados membros da UE. Tal operou mediante a consagração da cláusula geral de proteção de direitos fundamentais constante do atual n. 3 (anterior n. 2 e primitivamente n. ${ }^{\circ}$ ) do artigo $6 .^{\circ}$ (inicialmente artigo F) do TUE, inspirada na jurisprudência do TJ e onde avulta o conceito de princípios gerais de direito ${ }^{9}$.

Nessa medida, merece destaque a alteração introduzida no n. 2 da aludida disposição, na qual se prevê a adesão da UE à vulgarmente designada Convenção Europeia dos Direitos Humanos (doravante $\mathrm{CEDH}$ ), também objeto de uma

\footnotetext{
${ }^{6}$ Recorde-se que a inclusão da CDFUE no articulado do Tratado que pretendeu instituir uma Constituição para a Europa, assinado em 2004, foi uma das principais razões que contribuiu para o malogrado processo de ratificação deste, culminando com o seu abandono.

${ }^{7}$ Cfr. Ana Maria GUERRA MARTINS, Curso de Direito Constitucional da União Europeia, Coimbra, 2004, pág. 457, que enfoca precisamente o princípio da tutela jurisdicional efetiva como ratio legis subjacente aos direitos, princípios e garantias presentes no artigo $47 .^{\circ}$ da CDFUE.

${ }^{8}$ Cfr. Carlos CARRANHO PROENÇA, op. cit., págs. 52 e 53.

9 Ainda que a mesma, inicialmente, se apresentasse coartada de coercibilidade no que à atuação das instituições europeias dizia respeito (vide o artigo L do TUE), problema colmatado pelo Tratado de Amesterdão (vide a redação que este conferiu à alínea d) do então renumerado artigo 46. ${ }^{\circ}$, ex-artigo L, do TUE), o que teve repercussões ao nível da tutela jurisdicional efetiva no direito da União, que somente num segundo momento deixou de se apresentar relativizada.
} 
modificação no sentido de permitir tal participação ${ }^{10}$, onde se vislumbra um importante passo na consolidação do sistema comunitário de proteção dos direitos fundamentais ${ }^{11}$. Tal adesão é objeto de desenvolvimento no Protocolo n. ${ }^{\circ}$, anexo aos Tratados, relativo ao n. ${ }^{\circ} 2$ do artigo $6 .^{\circ}$ do TUE, que estabelece a necessidade de o acordo internacional inerente à participação da União na Convenção consagrar normas que assegurem as características próprias da UE e do respetivo direito ${ }^{12}$.

Além de possibilitar a substituição do método remissivo, atualmente vigente e constante do n. 3 do artigo $6^{\circ}$ do TUE, a adesão da UE à CEDH $(i)$ permitirá a fiscalização direta do direito da União (originário e derivado) pelo Tribunal Europeu dos Direitos Humanos (adiante TEDH); atualmente esse controlo, que assenta no princípio da responsabilidade coletiva dos Estados membros por atuações das instituições europeias contrárias à Convenção, é indireto ou reflexo e ocorre através dos atos nacionais de aplicação, execução ou transposição do direito da UE nas e para as ordens jurídicas nacionais.

A adesão da União à CEDH também (ii) sujeitará o TJ ao controlo jurisdicional levado a efeito pelo TEDH, órgão que representa o fim da linha ou a suprema instância em matéria de direitos fundamentais no espaço europeu.

Destaca-se ainda (iii) a possibilidade de os particulares se dirigirem ao TEDH, ao abrigo dos artigos 34. ${ }^{\circ}$ e seguintes da $\mathrm{CEDH}$, mediante petição ou queixa individual, com vista a obterem dele o reconhecimento do direito à reparação razoável por danos sofridos em consequência de atuações da UE contrárias aos direitos previstos na Convenção e nos seus protocolos adicionais, contando que o direito da União não permita, senão imperfeitamente, obviar às consequências de tais infrações.

\section{As alterações introduzidas na ação por incumprimento e no recurso de anulação}

Mesmo atuando sob o escopo do princípio da competência de atribuição, genericamente previsto no artigo $5^{\circ}$, n. $^{\text {os }} 1$ e 2 , do TUE e especificamente consagrado

\footnotetext{
${ }^{10} \mathrm{O}$ artigo $17 .^{\circ}$ do Protocolo Adicional n. ${ }^{\circ} 14$ da CEDH, em vigor desde 1 de junho de 2010, acrescentou um novo n..$^{\circ} 2$ ao seu artigo $59 .^{\circ}$, permitindo expressamente a adesão da UE à mesma.

${ }^{11}$ Sobre as vantagens da participação da UE na CEDH vide Carlos CARRANHO PROENÇA, op. cit., págs. 299 e 300.

${ }_{12}$ Alguns aspetos prendem-se com a eventual participação da União nas instâncias de controlo da Convenção (concretamente a existência de um juiz no Tribunal Europeu dos Direitos Humanos a nomear pela UE por força do artigo $20 .^{\circ}$ da CEDH e a participação da União no Comité de Ministros do Conselho da Europa); bem assim, com a existência de instrumentos que assegurem que as ações movidas por particulares e Estados terceiros sejam devidamente instauradas contra os Estados membros da UE e/ou contra esta.
} 
no âmbito da atuação do TJUE no artigo $274 .^{\circ}$ do TFUE, o qual é sinónimo de limitação competencial, as duas principais jurisdições em que se desdobra a instituição jurisdicional da UE - ou seja, o TJ e o TG, dado estarem dotados de competência genérica $^{13}$ - desempenham um papel fundamental no contexto da proteção jurisdicional efetiva na União. Bastará ter presente que as mesmas ( $i$ ) são permanentes, em regra (ii) assumem-se compulsórias (apenas excecionalmente se apresentam compromissórias) e, para o que agora mais releva, (iii) são exclusivas, não partilhando as suas prerrogativas com outras jurisdições, nomeadamente as nacionais.

No leque competencial do TJ e do TG, as ações por incumprimento e o recurso de anulação são dois instrumentos do tradicional contencioso europeu que, com a entrada em vigor do Tratado de Lisboa, conheceram alterações importantes com repercussões ao nível da tutela jurisdicional efetiva na União.

\subsection{Algumas inovações na ação por incumprimento}

A) No quadro jurídico renovado que passou a enformar a ação por incumprimento destaca-se, antes de mais, a ampliação do parâmetro de controlo da juridicidade europeia cujo respeito vincula os Estados membros. Se o anterior artigo 226. ${ }^{\circ}$ do Tratado da Comunidade Europeia (TCE) aludia às obrigações que incumbiam aos Estados membros "por força do presente Tratado", o artigo 258. do TFUE menciona obrigações que lhes "incumbem por força dos Tratados".

Além do Tratado de Roma, ressalta, no leque de textos de direito primário suscetíveis de violação pelos Estados membros, o Tratado de Maastricht. Com efeito e ressalvadas as disposições alusivas à Política Externa e de Segurança Comum (artigos $23 .^{\circ}$ a $46 .^{\circ}$ ), em relação às quais o artigo $24 .^{\circ}$ do TUE exclui genericamente a competência do TJUE, este Tratado prevê normas cuja imperatividade é inquestionável (designadamente o artigo $2 .^{\circ}$ alusivo aos valores democráticos), as quais podem ser objeto de violação pelos Estados, cenário que legitimará a Comissão, nos termos do artigo 258. ${ }^{\circ}$ do TFUE, ou os outros Estados membros, como preceituado no artigo $259 .^{\circ}$ do mesmo Tratado, a despoletarem no TJ a ação por incumprimento.

\footnotetext{
${ }^{13}$ De fora fica o Tribunal da Função Pública, provido de competência específica para os litígios de natureza laboral entre os funcionários e as instituições, os órgãos ou organismos europeus onde desenvolvem as suas funções.
} 
Sem embargo de a solução agora positivada ser já defensável mesmo no quadro jurídico-institucional que vigorou até ao Tratado de Lisboa, o esclarecimento trazido a lume por este Tratado merece uma nota positiva.

B) No entanto, não deixará de merecer um reparo, apesar de tudo corrigível pelo intérprete e aplicador dos Tratados (com particular destaque para os tribunais organicamente da UE, em especial o TJ dado só ele ter competência para as ações por incumprimento), a incoerência entre o n. ${ }^{\circ} 1$ do artigo $260 .^{\circ}$ e o primeiro parágrafo do artigo 258. ${ }^{\circ}$, ambos do TFUE. Se este alude ao desrespeito, pelos Estados membros, das obrigações que lhes incumbem por força dos Tratados, aquele refere que o TJ pode, no seu acórdão, declarar que os aludidos sujeitos não cumpriram vinculações a que estão adstritos por força do TFUE apenas. $\mathrm{O} \mathrm{n} .^{\circ} 1$ do artigo $260 .^{\circ}$ deve, consequentemente, ser objeto de uma interpretação extensiva, em consonância com a alteração efetuada ao artigo 258. ${ }^{\circ}$ pelo Tratado de Lisboa e de acordo com um espírito que melhor favorece a tutela jurisdicional efetiva, no sentido de o mencionado órgão também poder declarar que um Estado membro não cumpriu as obrigações que lhe incumbem por força dos Tratados.

C) Por outro lado, apresenta-se discutível a questão de saber se os acórdãos proferidos pelo TJ em sede da chamada segunda ação por incumprimento (ou ação de segundo grau), e nos quais sejam aplicadas sanções pecuniárias aos Estados membros arguidos pelo desrespeito das decisões emanadas do mesmo órgão jurisdicional no âmbito da primeira ação são, ou não, título executivo. A tutela jurisdicional efetiva exige, no mínimo, resposta afirmativa ${ }^{14}$. Na verdade, tendo os Estados membros assentido na inserção no TFUE de uma disposição como a do segundo parágrafo do n. $^{\circ}$ 2 do artigo $260 .^{\circ}$, não faria sentido que o acatamento das condenações determinadas pelo TJ estivesse dependente da boa vontade daqueles. Dissemos "no mínimo", na medida em que a cobrança coerciva de tais quantias, talvez, nem sequer deva carecer da instauração de ações executivas, caracterizadas por alguma morosidade, além de serem meramente eventuais, podendo operar através de outras formas mais céleres, designadamente a compensação nos montantes que o Estado membro infrator receberia a título de fundos comunitários.

D) Bastante positiva, apenas pecando por tardia, afigura-se a inovação trazida a lume pelo Tratado de Lisboa e constante do n. 3 do artigo $260 .^{\circ}$ do TFUE. Prevê-se

\footnotetext{
${ }^{14}$ Neste sentido Lauria FELICETTA, Manuale di Diritto delle Comunità Europee, 3. ${ }^{\text {a }}$ edição, Milão, 1992, pág. 361; Maria José RANGEL DE MESQUITA, O Poder Sancionatório da União e das Comunidades Europeias sobre os Estados Membros, Coimbra, 2006, pág. 236.
} 
aqui que, no âmbito da mesma ação por incumprimento instaurada ao abrigo do artigo 258..$^{\circ}$ do mesmo Tratado, a Comissão possa indicar desde logo o montante da sanção pecuniária que considera adequado à infração, de forma a permitir ao TJ, caso declare a violação de obrigações decorrentes do direito da União, condenar imediatamente o Estado membro no seu pagamento, podendo a sanção ser fixada abaixo do valor proposto. Desta forma, a tutela jurisdicional efetiva da objetiva legalidade europeia obteve um bom incremento ${ }^{15}$.

Ressalve-se, contudo, que o âmbito de aplicação daquele cenário peca por escasso e apresenta algumas limitações. Antes de mais, a referida ação deve ser proposta ao abrigo do artigo $258 .^{\circ}$ do Tratado de Roma, o que inculca que as ações por incumprimento marcadas por fases administrativas especiais ${ }^{16}$, ou nas quais a fase graciosa pode ser preterida $^{17}$, situam-se fora da sua previsão. Por outro lado, ela apenas pode ter lugar no que tange ao não cumprimento da obrigação de comunicação de medidas nacionais de transposição de diretivas adotadas de acordo com um processo legislativo; a contrario sensu, incumprimentos da obrigação de comunicação de medidas internas de receção de atos não legislativos, como sejam os atos delegados e os atos de execução, situam-se fora da facti species da norma ${ }^{18}$; igualmente, outros tipos de incumprimentos não relevam.

Por outro lado ainda, também aqui avulta o poder discricionário da Comissão, uma vez que esta poderá, "se o considerar adequado", indicar o valor da sanção a aplicar ao Estado membro; em homenagem ao princípio do dispositivo, o TJ poderá, caso confirme o cometimento da infração, condenar o Estado, respeitando o valor indicado pela Comissão, já que não poderá excedê-lo, diversamente do que ocorre no quadro do n. ${ }^{\circ} 2$ do artigo $260 .^{\circ}$ do TFUE $^{19}$.

\footnotetext{
${ }^{15}$ Cfr. Luca PRETE e Ben SMULDERS, The Coming of Age of Infringement Proceedings, in Common Market Law Review, 2010 (Vol. 47; n. ${ }^{\circ}$ 1), págs. 9 e ss.

${ }^{16}$ Designadamente, a ação por incumprimento prevista no $n .^{\circ} 2$ do artigo $108 .^{\circ}$ do TFUE, ou seja, no domínio dos auxílios de Estado.

${ }^{17}$ Nomeadamente, a ação por incumprimento prevista no artigo $348 .^{\circ}$ do TFUE.

${ }^{18}$ Cfr. Miguel GORJÃO-HENRIQUES, Direito da União, 6. ${ }^{a}$ edição, Coimbra, 2010, págs. 493 e 494.

${ }^{19}$ Maria José RANGEL DE MESQUITA denuncia o protagonismo conferido a um incumprimento que pode ser meramente formal e a falta de tratamento idêntico entre este e um incumprimento material traduzido na não transposição de diretivas; a autora também critica a mera faculdade de que a Comissão dispõe, no âmbito do n. $^{\circ} 3$ do artigo $260 .^{\circ}$ do TFUE, de indicar o montante da sanção pecuniária (fixa ou compulsória) a aplicar ao Estado alegadamente infrator, diversamente do que sucede no quadro do n. ${ }^{\circ} 2$ do mesmo preceito, que impõe àquela instituição o dever de proceder a tal indicação; bem como a vinculação do TJ ao montante sancionatório fornecido pela Comissão no âmbito de uma competência que é de plena jurisdição. Cfr. O sistema jurisdicional após o Tratado de Lisboa, in AA. VV, O Tratado de Lisboa. Jornadas organizadas pelo Instituto de Ciências Jurídico-Políticas da Faculdade de Direito da Universidade de Lisboa, Coimbra, 2012, págs. 79 a 81.
} 
Seja como for, a tutela jurisdicional efetiva exige a ampliação do âmbito material de aplicação desta disposição, devendo ser ponderada a (des)necessidade de instauração de duas ações por incumprimento: uma, a primeira (ou ação de primeiro grau), de finalidade meramente declarativa de simples apreciação; outra, a segunda (ou ação de segundo grau), de desígnio condenatório. A tutela jurisdicional efetiva requer que se habilite o TJ a poder condenar o Estado membro incumpridor de obrigações decorrentes do direito da UE no pagamento de sanções pecuniárias no quadro da mesma ação por incumprimento. A inovação trazida a lume pelo Tratado de Lisboa, constante do n. ${ }^{\circ} 3$ do artigo $260 .^{\circ}$ do TFUE, servirá de laboratório a possíveis futuros alargamentos do âmbito material previsto na mencionada disposição.

\subsection{Algumas inovações no recurso de anulação}

No âmbito do recurso de anulação, com o Tratado de Lisboa, os Estados membros atenuaram uma "séria lacuna no sistema de vias de recurso estabelecido no Tratado"20, problema assim qualificado sobretudo devido ao requisito constante do quarto parágrafo do ex-artigo $230 .^{\circ}$ do TCE e tradicionalmente exigido para a admissibilidade dos recursos interpostos pelas pessoas singulares e coletivas, relativo à afetação individual por estas pelos designados "falsos" regulamentos, ou seja, atos que apesar de adotados sob a forma regulamentar, materialmente consubstanciam verdadeiras decisões dada a ausência, ainda que parcial, de alcance geral.

Assim, em sede de via anulatória, o primeiro (e o principal) aspeto com repercussões ao nível da tutela jurisdicional efetiva na UE prende-se com a reformulação do quarto parágrafo do artigo $263 .^{\circ}$ do TFUE, o qual apresenta uma redação renovada pelo Tratado de Lisboa e de acordo com a qual "Qualquer pessoa singular ou colectiva pode interpor, nas condições previstas nos primeiro e segundo parágrafos, recursos contra os actos de que seja destinatária ou que lhe digam directa e individualmente respeito, bem como contra actos regulamentares que lhe digam directamente respeito e não necessitem de medidas de execução".

Face à composição precedente são visíveis duas alterações. Por um lado, a expressão "decisões" surge substituída pelo termo "atos", o que à partida inculca uma

\footnotetext{
${ }^{20}$ Vide as conclusões apresentadas pelo Advogado-geral F. G. JACOBS, em 21 de Março de 2002, no contexto caso Unión de Pequeños Agricultores vs. Conselho, proc. C-50/00 P, Col. 2002, pág. I-6682, no qual a questão material controvertida centrou-se, precisamente, nas limitações dos particulares na interposição de recursos de anulação contra regulamentos comunitários.
} 
maior abrangência do objeto do recurso de anulação; abandonou-se, portanto, a configuração tradicional segundo a qual os atos que afetavam direta e individualmente os recorrentes ordinários - ou não privilegiados - não sendo estes os respetivos destinatários $^{21}$, surgiam, formal ou materialmente, sob o modelo da decisão. Por outro lado, a necessidade de esta categoria de recorrentes (normalmente particulares) ser direta e individualmente afetada pelos atos impugnados, ressalvados aqueles de que sejam destinatários, mantendo-se para a generalidade dos atos suscetíveis de constituir objeto do recurso de anulação, sofreu, ainda que parcialmente, uma importante remodelação no que tange aos agora chamados "atos regulamentares".

O segmento final do aludido quarto parágrafo do artigo $263 .^{\circ}$ do Tratado de Roma regula a impugnação daquilo que aí se designa de "actos regulamentares" que digam diretamente respeito ao recorrente e não careçam de medidas de execução, ainda que sem fornecer ao intérprete o respetivo conceito. É precisamente em relação à impugnação desta "nova" tipologia de atos que são visíveis as maiores alterações à mencionada disposição, pelo que importa saber o que se deve entender por atos regulamentares.

Um setor doutrinário autorizado entende que a norma tem por escopo todos os regulamentos, o que indubitavelmente prossegue melhor a tutela jurisdicional efetiva ${ }^{22}$.

Entendemos, no entanto, que a interpretação da renovada disposição é outra. Note-se que, ao invés do que sucede com o primeiro parágrafo do artigo 288 . $^{\circ}$ do TFUE, o quarto parágrafo do artigo $263 .^{\circ}$ alude a atos regulamentares e não a regulamentos, podendo questionar-se se aqueles são, ou não, todos os regulamentos na aceção do referido artigo $288 .^{\circ}$, naturalmente pressupondo que os mesmos dizem diretamente respeito ao recorrente e não necessitam de medidas de execução.

Como nota Maria Luísa DUARTE ${ }^{23}$, os artigos $289 .^{\circ}$ e seguintes do TFUE contrapõem, na nova tipologia dos atos jurídicos da UE, os atos legislativos aos atos não legislativos (vide artigo $290 .^{\circ},{ }^{\circ} .^{\circ}$ ), podendo estes últimos ser delegados (artigo $290 .^{\circ}$, n. $^{\text {os }} 2$ e 3 ) ou de execução (artigo $291 .^{\circ}$, n. $^{\text {os }} 2$ a 4); no entanto, tais disposições

\footnotetext{
${ }^{21}$ Tanto os referidos "falsos regulamentos" (ou seja, "verdadeiras decisões" embora adotadas sob a forma regulamentar) como as decisões dirigidas a outra pessoa.

${ }^{22}$ Cfr. Jónatas MACHADO, Direito da União Europeia, Coimbra, 2010 pág. 538; Stephan BALTHASAR, Locus Standi Rules for Challenges to Regulatory Acts by Private Applicants: the New Article 263(4) TFEU, in European Law Review, 2010 (Vol. 35; n. o 4), págs. 546 e 547; e Koen LENAERTS e Nathan CAMBIEN, Regions and the European Court: Giving Shape to the Regional Dimension of the Member States, in European Law Review, 2010 (Vol. 35; n. ${ }^{\circ}$ 5), págs. 616 e 617.

${ }^{23}$ Cfr. A União Europeia e o sistema europeu de protecção dos direitos fundamentais - A chancela do Tratado de Lisboa, in Estudos sobre o Tratado de Lisboa, Coimbra, 2010, pág. 108, nota de rodapé 32. No mesmo sentido Jean-Luc SAURON, Comprendre le Traité de Lisbonne, Paris, 2008, pág. 90.
} 
não aludem aos atos regulamentares ${ }^{24}$; por outro lado, do cotejo entre o primeiro e o quarto parágrafos do artigo 263..$^{\circ}$ do TFUE surge a contraposição entre atos legislativos, mencionados naquele, e atos regulamentares, referidos neste ${ }^{25}$. Ora, pressupondo que o ato regulamentar não carece de medidas de execução, parece-nos que nem todos os regulamentos estarão subjacentes à parte final do quarto parágrafo do artigo $263 .^{\circ}$ do TFUE, encontrando-se excluídos os atos legislativos ${ }^{26}$, isto é, os regulamentos que resultem da designada "atividade legislativa de base" ${ }^{\text {"27 }}$ da UE. Estes são impugnáveis nos termos do segmento intermédio do quarto parágrafo do mencionado artigo $263 .^{\circ}$, devendo o recorrente ordinário demonstrar, como já o fazia no quadro jurídico anterior ao Tratado de Lisboa, que o ato lhe diz direta e individualmente respeito. Pela positiva, das várias espécies de atos daquele género com que as pessoas singulares ou coletivas se podem deparar, estarão em causa os regulamentos de execução e os regulamentos delegados que, assumindo natureza administrativa ${ }^{28}$, são da autoria da Comissão. Um domínio propício à adoção destes tipos de atos é o relativo à proteção da concorrência, que encontra base jurídica nos artigos $101 .^{\circ}$ e $102 .^{\circ}$ do TFUE ${ }^{29}$.

Seja como for e por contraposição aos atos legislativos, mantém-se a exigência de os ora chamados atos regulamentares dizerem diretamente respeito às pessoas singulares ou coletivas que os pretendam impugnar, tendo desaparecido a necessidade da sua afetação de forma individual ${ }^{30}$, o que aumenta a possibilidade de os recorrentes não privilegiados serem visados por eles, assim se reforçando a tutela jurisdicional efetiva dos seus direitos subjetivos e interesses legítimos.

\footnotetext{
${ }^{24}$ Assim também Albertina ALBORS-LLORENS, Remedies against the EU Institutions after Lisbon: An Era of Opportunity, in The Cambridge Law Journal, 2012 (Vol. 71; n. 3 3), pág. 520.

${ }^{25}$ Ainda que elaborado a propósito de uma classificação dos atos jurídicos (legislativos e não legislativos) da UE que seria introduzida pelo abandonado Tratado Constitucional Europeu, de 2004, na qual sobressaía o surgimento da "lei europeia" em substituição do tradicional regulamento comunitário, relegando este para a categoria dos atos normativos de natureza não legislativa, bem como da "lei-quadro europeia" modificando a clássica diretiva comunitária, vide Koen LENAERTS e Marlies DESOMER, Towards a Hierarchy of Legal Acts in the European Union? Simplification of Legal Instruments and Procedures, in European Law Journal, 2005 (Vol. 11; n. ${ }^{\circ}$ 6), págs. 744 e ss.

${ }^{26}$ Neste sentido Jean Paul JACQUÉ, Droit institutionnel de l'Union européenne, 6. edição, Paris, 2010, pág. 650; Floris de WITTE, The European Judiciary after Lisbon, in Maastricht Journal of European and Comparative Law, 2008 (Vol. 15; n. ${ }^{\circ}$ 1), págs. 46 e 47; Francisco PAES MARQUES, $O$ acesso dos particulares ao recurso de anulação após o Tratado de Lisboa: remendos a um fato fora de moda, in Cadernos O Direito, n. ${ }^{\circ}$ 5, 2010, págs. 101 e 102. Com a mesma orientação vide o despacho do TG, caso Inuit Tapiriit Kanatami e o. vs. Parlamento Europeu e Conselho, de 6 de setembro de 2011, proc. T18/10, Col. 2011, págs. II-5599 e ss, n. ${ }^{\circ}$ 56; bem como o acórdão do TG, caso Microban vs. Comissão, de 25 de outubro de 2011, proc. T-262/10, Col. 2011, págs. II-7697 e ss, n. ${ }^{\circ} 21$.

27 Cfr. F. G. JACOBS nas conclusões apresentadas no caso Unión de Pequeños Agricultores vs. Conselho, pág. I-6710.

${ }^{28}$ Cfr. Ricardo ALONSO GARCÍA, Sistema Jurídico de la Unión Europea, Pamplona, 2007, pág. 159; Albertina ALBORS-LLORENS, op. cit., pág. 521.

${ }^{29}$ Cfr. Carlos CARRANHO PROENÇA, op. cit., pág. 471.

${ }^{30}$ Cfr. Maria José RANGEL DE MESQUITA, $O$ sistema ..., cit., pág. 82.
} 


\section{A consagração do direito dos particulares à proteção jurisdicional efetiva nos domínios do direito da União Europeia}

Sem embargo dos direitos e dos princípios, bem como das garantias, previstos no artigo 47. ${ }^{\circ}$ da CDFUE (entre outros, direitos de ação e de defesa, direito a um processo justo e equitativo, princípio do juiz legal ou natural, garantia da independência e imparcialidade dos órgãos jurisdicionais) ${ }^{31}$, aos quais subjaz o princípio da tutela jurisdicional efetiva, a positivação expressa nos Tratados de tal proteção enquanto direito fundamental dos particulares, nas matérias que recaem nas atribuições da UE, também se deve ao Tratado de Lisboa, constando do segundo parágrafo do $n .^{\circ} 1$ do artigo 19. ${ }^{\circ}$ do TUE, segundo o qual "Os Estados membros estabelecem as vias de recurso necessárias para assegurar uma tutela jurisdicional efetiva nos domínios abrangidos pelo direito da União".

Esta disposição exorta os Estados integrantes da UE, enquanto entes soberanos dotados de tribunais encarregados do exercício da função judicial nos respetivos territórios e de legisladores democráticos incumbidos de elaborar as leis internas de processo, a garantir uma salvaguarda jurisdicional útil e eficaz (ou seja, plena) sobretudo dos direitos subjetivos e dos interesses legítimos conferidos aos particulares pela ordem jurídica da União, mas também da objetiva legalidade europeia. Numa União de direito, composta por Estados membros igualmente de direito, as pretensões de natureza subjetiva (direitos, principalmente fundamentais, e interesses legítimos) atribuídas pela respetiva ordem jurídica não podem esbarrar em obstáculos relacionados com a inexistência de órgãos jurisdicionais competentes para o seu reconhecimento ou com a falta de leis adjetivas e de instrumentos processuais através dos quais tais pretensões são realizadas judicialmente ${ }^{32}$. Em homenagem ao velho brocardo ubi ius ibi remedium, a que o ordenamento da UE não pode ser alheio, aos direitos reconhecidos por este devem corresponder vias adjetivas que permitam efetivá-los.

No entanto, o alcance da norma parece cingir-se às situações jurídicas existentes nos e face aos Estados membros, bem assim entre particulares, desde que reguladas pelo direito europeu; aliás, a exigência que resulta da disposição decorre o princípio da

\footnotetext{
${ }^{31}$ Sobre eles vide Carlos CARRANHO PROENÇA, op. cit., pág. 64 e segs.

${ }^{32}$ Cfr. o comentário ao artigo $19 .^{\circ}$ do TUE de José Narciso da CUNHA RODRIGUES e António José ROBALO CORDEIRO, pág. 98, in Manuel LOPES PORTO e Gonçalo ANASTÁCIO (coordenação), Tratado de Lisboa. Anotado e comentado, Coimbra, 2012.
} 
cooperação leal, hoje consagrado no n. 3 do artigo $4 .^{\circ}$ do TUE, nitidamente vocacionado para os Estados membros enquanto partes integrantes da União.

A norma não abrange, pelo menos no seu teor literal, as situações entre os particulares e a UE. Tal dever-se-á ao facto de, normalmente, o direito da União produzir efeitos jurídicos na esfera dos particulares através de atos nacionais de aplicação ou de execução, em homenagem ao princípio da aplicação descentralizada do direito europeu, decorrente do princípio da subsidiariedade. Ainda assim e sem prejuízo das consagrações implícitas da tutela jurisdicional efetiva enquanto direito dos particulares face à União, constantes designadamente do quarto parágrafo do artigo $263 .^{\circ}$ ou dos artigos $267 .^{\circ}$ e $277 .^{\circ}$, todos do TFUE, a vinculação desta a um direito dos particulares à aludida proteção jurisdicional não deixará de constar do espírito do segundo parágrafo do artigo $19 .^{\circ}$ do TUE.

\section{O Tratado de Lisboa enquanto ocasião perdida de reforço da tutela jurisdicional efetiva na União Europeia}

Sem embargo destas inovações, os Estados membros não aproveitaram o Tratado de Lisboa para procederem a determinadas opções políticas, algumas há muito reivindicadas, precisamente no seio dos dois instrumentos do tradicional contencioso europeu acima aludidos, as quais reforçariam a proteção jurisdicional efetiva no quadro jurídico-institucional da UE. Neste aspeto, o mencionado Tratado não deixou de representar (mais) uma oportunidade desperdiçada para a introdução de certas modelações que contribuíram para alcançar aquele desiderato.

A) Nomeadamente em sede de ação por incumprimento, o TJ deveria poder conformar, ao menos não vinculadamente ou, se se preferir, de forma sugestiva a execução do seu acórdão declarativo de incumprimento por parte do Estado membro cujo comportamento foi declarado incompatível com os Tratados ${ }^{33}$. Isto porque, no atual quadro, o TJ limita-se a declarar a existência, ou não, de incumprimento de obrigações decorrentes daqueles ou do direito derivado, competindo depois ao Estado “tomar as medidas necessárias à execução do acórdão do Tribunal" (vide o n. 1 do artigo 260. ${ }^{\circ}$ do TFUE). Ora, admitindo-se à Comissão, quando decide despoletar a segunda ação por incumprimento, que comece por enunciar algumas prestações de facto

33 Tivemos oportunidade de fazer esta sugestão na nossa dissertação de doutoramento. Cfr. Carlos CARRANHO PROENÇA, op. cit., pág. 426. Ver também Maria José RANGEL DE MESQUITA, $O$ Poder..., cit., págs. 181 e 210. 
que o Estado membro poderia ter adotado com vista à adoção das referidas medidas, o que aliás faz em decorrência do preceituado na primeira parte do.$^{\circ} 2$ do artigo $260 .^{\circ}$, porque não habilitar o TJ a, pelo menos, sugerir prestações de facto que o Estado membro pudesse tomar no sentido de fazer cessar a situação de incumprimento declarada no seu acórdão? Tal prerrogativa teria provavelmente o mérito de poder contribuir para a prevenção da instauração de algumas ações por incumprimento de segundo grau.

B) Designadamente no âmbito do recurso de anulação e muito embora a ampliação do leque de recorrentes institucionais, ainda que dotados de uma legitimidade ativa mitigada (isto é, cujos recursos interpostos estão sujeitos à contingência de se destinarem a salvaguardar as respetivas prerrogativas competenciais), verificada em relação ao Comité das Regiões (vide o terceiro parágrafo do artigo $263 .^{\circ}$ do TFUE), o Provedor de Justiça Europeu permanece desprovido de legitimidade processual para poder interpor, em representação dos cidadãos europeus, recursos de anulação ao menos contra atos legislativos. O referido órgão deveria adquirir tal competência ${ }^{34}$, tanto mais que em alguns sistemas jurídicos nacionais ( $v . g$. o português) os provedores de justiça podem despoletar o processo sucessivo, abstrato e concentrado de fiscalização da constitucionalidade de normas (em Portugal vide o artigo 281. ${ }^{\circ}$, n. $^{\circ} 1$ e n. ${ }^{\circ} 2$, alínea d), da Constituição da República), em relação ao qual o recurso de anulação previsto no Tratado de Roma apresenta algumas semelhanças, nomeadamente a de servir de instrumento de controlo do respeito pelo princípio da hierarquia dos atos normativos europeus, concretamente a conformidade dos regulamentos, das diretivas e decisões (ou do direito derivado) face ao mencionado Tratado (ou mais amplamente face ao direito primário).

Ainda no quadro do recurso de anulação, os Estados membros deveriam igualmente ponderar o alargamento da legitimidade ativa, pelo menos, a associações representativas de determinados interesses públicos, no contexto de situações jurídicas onde esteja em causa a tutela dos chamados interesses coletivos difusos, isto é, de posições que não atingem um nível suficiente de concretização subjetiva, reclamando por isso uma tutela pública e coletiva, algo que remonta à figura da ação popular existente em alguns sistemas jurídicos nacionais ${ }^{35}$. A salvaguarda ambiental e a proteção dos consumidores são indubitavelmente domínios que requerem essa

\footnotetext{
${ }^{34}$ Igualmente na nossa tese de doutoramento defendemos esta alteração. Cfr. Carlos CARRANHO PROENÇA, op. cit., págs. 44, 77 e 473.

${ }^{35}$ Cfr. Jónatas MACHADO, op. cit., p. 529; Carlos CARRANHO PROENÇA, op. cit., pág. 475.
} 
ampliação, a qual permitiria reforçar, de outra banda, o estatuto de cidadania europeia (atualmente fracionado entre os artigos $9 .^{\circ}$ a $11 .^{\circ}$ do TUE e os artigos $20 .^{\circ}$ a $25 .^{\circ}$ do TFUE). Aliás, dissemos "pelo menos" precisamente porque não nos chocaria a consagração de tal prerrogativa no leque dos direitos dos cidadãos da União.

Por outro lado ainda e com vista a alcançar-se a execução dos acórdãos anulatórios a que alude o artigo $266^{\circ}$ do TFUE, o TJ poderia ser investido, naturalmente em sede de revisão do aludido Tratado, nas prerrogativas $(i)$ de aplicar sanções pecuniárias compulsórias às instituições, uma vez que já o pode fazer em relação aos Estados membros (precisamente por não terem conferido a devida execução aos acórdãos do TJ, se bem que declarativos de situações de incumprimento de obrigações resultantes do direito da União e no quadro da inerente ação), bem como (ii) de conformar a execução do seu acórdão anulatório, sugerindo-lhes prestações de facto. Tais medidas certamente contribuirão para que a aludida execução seja alcançada de uma forma mais célere e eficaz.

\section{A inversão da jurisprudência Foto-frost como reforço da tutela jurisdicional efetiva na União Europeia}

Decorria o ano de 1987 quando o TJ estabeleceu, no célebre acórdão Foto-frost ${ }^{36}$, o monopólio da sua jurisdição para declarar a invalidade de normas europeias no quadro do reenvio prejudicial, instrumento processual onde também participam os órgãos jurisdicionais nacionais, sendo, aliás, despoletado por estes. A competência daquele órgão para declarar a invalidade de normas constantes de atos europeus de direito derivado caracteriza-se, portanto, pela exclusividade, o que é particularmente visível nas questões prejudiciais de validade. Assim, os órgãos jurisdicionais estaduais apenas podem desaplicar os atos nacionais contrários ao direito da União, não dispondo de idêntica faculdade relativamente às disposições europeias nem de competência para declarar a invalidade dos atos das instituições, dos órgãos ou organismos da União.

Determinando que os juízes dos Estados membros, ao depararem-se com dúvidas sobre a validade de atos das instituições europeias, não poderão declará-los inválidos nem desaplicá-los, devendo antes submeter as inerentes questões prejudiciais, o TJ

\footnotetext{
36 Acórdão de 22 de outubro de 1987, processo 314/85, Col. 1987, págs. 4225 e segs, o qual foi confirmado, designadamente, pelos arestos Zuckerfabrik, de 21 de fevereiro de 1991, processos apensos C-143/88 e C-92/89, Col. 1991, págs. I-534 e segs, e Woodspring vs. Bakers of Nailsea, de 15 de abril de 1997, processo C-27/95, Rec. 1997, págs. I-1857 e segs.
} 
acrescentou ainda que este procedimento deve ter lugar mesmo quando das decisões dos órgãos jurisdicionais nacionais caiba recurso, acrescentando assim, para estes, uma obrigação de reenvio que não decorre da letra do terceiro parágrafo do artigo $267 .^{\circ}$ do TFUE.

Não se tratando o reenvio de um processo contencioso, dada a ausência de litígio, nem de um processo de partes, tal como não é nenhuma ação nem qualquer recurso, sendo antes um processo de cooperação institucional entre os tribunais nacionais e o $T J$ que assenta no respeito mútuo, bem como num relacionamento horizontal entre a jurisdição do TJ e as jurisdições nacionais, e não em verticalização nem em hierarquia, o verdadeiro e pleno estatuto reconhecido aos órgãos jurisdicionais nacionais de tribunais comuns da ordem jurídica da $U E^{37}$ exige uma alteração daquele entendimento jurisprudencial e o reconhecimento a estes da prerrogativa para declararem a invalidade de disposições europeias, ainda que mediante a observância de alguns requisitos.

Tendo em vista a proteção da unidade e da aplicação uniforme do direito da UE, a segurança jurídica e o primado das decisões do TJ sobre matéria de invalidade de atos das instituições, dos órgãos ou organismos europeus, argumentos invocados por aquele tribunal para justificar o seu "monopólio" na declaração de invalidade de disposições europeias, naturalmente que o reconhecimento de tal faculdade aos órgãos jurisdicionais dos Estados membros poderia ser mitigado ( $i$ ) através da eficácia restrita de tais decisões, isto é, de efeitos meramente inter partes ou limitados ao caso concreto; bem assim (ii) com a possibilidade de as instâncias superiores, em caso de interposição de recurso ordinário nos termos do direito interno, alterarem ou confirmarem o sentido da decisão de invalidade oriunda das instâncias inferiores; ainda coadjuvada (iii) com a obrigatoriedade, decorrente do terceiro parágrafo do artigo $267 .^{\circ}$ do TFUE, para os órgãos jurisdicionais nacionais que se ocupassem do processo em última instância de colocar a questão prejudicial ao TJ, para que este confirmasse ou infirmasse os julgamentos de invalidade feitos pelas jurisdições estaduais ${ }^{38}$; (iv) eventualmente,

\footnotetext{
${ }^{37}$ Entre muitos outros, recordem-se os acórdãos Simmenthal, de 9 de março de 1978, proc. 106/77, Col. 1978, págs. 243 e segs; Factortame, de 19 de junho de 1990, proc. C-213/89, Col. 1990, págs. I-2433 e segs; do TG, veja-se o aresto Tetra Pak, de 10 de julho de 1990, proc. T-51/89, Col. 1990, págs. II-309 e segs.

${ }^{38}$ Há autores que propalam um modelo onde os órgãos jurisdicionais nacionais possam interpretar e apreciar a validade do direito da UE, semelhante ao que sucede nos sistemas de fiscalização concreta e difusa de constitucionalidade, com recurso para o TJ. Neste sentido Carol HARLOW, A Common European Law of Remedies?, in Claire KILPATRICK, Tonia NOVITZ e Paul SKIDMORE (editors), The Future of Remedies in Europe, Oxford, 2000, págs. 81 e ss; entre nós, VITAL MOREIRA, A tutela dos direitos fundamentais na União Europeia, in AA. VV, Carta de Direitos Fundamentais da União Europeia, Coimbra, 2001, pág. 78.
} 
prevendo-se um reenvio obrigatório a submeter pelo órgão jurisdicional estadual que desaplicasse o ato europeu; e, enfim, $(v)$ com uma reserva da força obrigatória geral para os juízos de invalidade da autoria do $\mathrm{TJ}^{39}$.

Justificar-se-á com certeza que o TJ tenha a última palavra em matéria de invalidade de atos da União de direito derivado, bem como que as suas decisões, enquanto órgão especializado, prevaleçam sobre as dos tribunais nacionais; o que parece não ter muita razão de ser é que somente aquele disponha de uma competência absolutamente exclusiva sobre invalidade da normatividade europeia ${ }^{40}$, principalmente quando admite que os tribunais dos Estados membros podem concluir pela sua validade.

A inversão da jurisprudência Foto-frost adequar-se-ia ao novo segundo parágrafo do n. 1 do artigo 19. ${ }^{\circ}$ do TUE, estimulando os Estados membros, enquanto entes soberanos dotados de legisladores democráticos e de órgãos a quem compete o exercício do poder judicial, a preverem as adequadas e necessárias vias de acesso aos tribunais para aí verem salvaguardados os direitos subjetivos e os interesses legítimos que a ordem jurídica da União lhes reconhece.

\section{Conclusão}

A proteção jurisdicional efetiva no sistema jurídico da UE conheceu importantes desenvolvimentos com o Tratado de Lisboa, destacando-se, desde logo, a referência expressa que lhe é dedicada no segundo parágrafo do $n .^{\circ} 1$ do artigo $19 .^{\circ}$ do TUE. Nesta disposição, no entanto, tal tutela apresenta-se como um direito dos particulares face aos Estados membros enquanto extensão da Administração Pública europeia, a qual, em regra, funciona de acordo com o modelo de administração indireta decorrente do princípio da aplicação descentralizada do direito europeu (e mais amplamente do próprio princípio da subsidiariedade). Tal modelo implica que o direito da UE normalmente produza efeitos na esfera jurídica dos particulares através de atos nacionais de aplicação ou de execução. Daí a relevância de as instituições e de os órgãos e organismos europeus, bem como os Estados membros quando aplicam ou executam direito da UE, estarem sujeitos à CDFUE, a qual, com o Tratado de Lisboa, adquiriu um estatuto jurídico vinculativo. Neste campo, porém, continua a existir margem para aperfeiçoar o sistema europeu de proteção jurisdicional de direitos fundamentais,

\footnotetext{
${ }^{39}$ Cfr. Miguel GORJÃO-HENRIQUES, op. cit., págs. 513 e 514.

${ }^{40}$ Contra FAUSTO DE QUADROS, Direito da União Europeia, 3. a edição, Coimbra, 2013, pág. 599.
} 
sugerindo-se a concretização da adesão da União à CEDH. Também propomos a alteração da jurisprudência Foto-frost, através do reconhecimento aos tribunais nacionais da prerrogativa de julgarem inválidas as disposições europeias, o que será um contributo para a consolidação da sua atuação enquanto órgãos jurisdicionais comuns do ordenamento da União.

Naturalmente, o princípio da proteção jurisdicional efetiva também releva quando a UE atua segundo o modelo de administração direta ( $v . g$. no domínio da concorrência) ou no quadro de outras funções diferentes da função administrativa (v. $g$. a legislativa). Nesses âmbitos são os instrumentos do tradicional contencioso europeu (entre eles, as ações por incumprimento e o recurso de anulação) que permitem prosseguir tal desiderato, os quais conheceram importantes contributos com o Tratado de Lisboa, mas onde continua a existir larga margem para poderem ser melhorados, como seja o reconhecimento ao Provedor de Justiça Europeu da prerrogativa de impugnar atos de direito derivado em representação dos cidadãos da União ou a eliminação da necessidade de o sancionamento dos Estados membros ter de passar pela instauração encadeada e interdependente de duas ações por incumprimento de finalidades complementares.

\section{Bibliografia}

ALBORS-LLORENS, Albertina - Remedies against the EU Institutions after Lisbon:

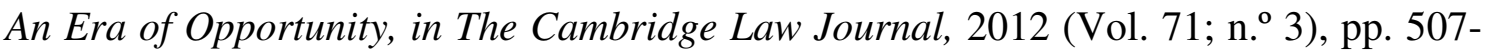
536.

ALONSO GARCÍA, Ricardo - Sistema Jurídico de la Unión Europea, Pamplona, 2007.

BALTHASAR, Stephan - Locus Standi Rules for Challenges to Regulatory Acts by Private Applicants: the New Article 263(4) TFEU, in European Law Review, 2010 (Vol. 35 ; n. $\left.{ }^{4}\right)$, pp. 542-550.

DUARTE, Maria Luísa - A União Europeia e o sistema europeu de protecção dos direitos fundamentais - A chancela do Tratado de Lisboa, in Estudos sobre o Tratado de Lisboa, Coimbra, 2010, pp. 91-115. 
FELICETTA, Lauria - Manuale di Diritto delle Comunità Europee, 3. ${ }^{a}$ edição, Milão, 1992.

GORJÃO-HENRIQUES, Miguel - Direito da União, 6. ${ }^{\text {a }}$ edição, Coimbra, 2010.

HARLOW, Carol - A Common European Law of Remedies?, in Claire KILPATRICK, Tonia NOVITZ e Paul SKIDMORE (editors), The Future of Remedies in Europe, Oxford, 2000, pp. 69-86.

JACQUÉ, Jean Paul - Droit institutionnel de l'Union européenne, 6. ${ }^{a}$ edição, Paris, 2010 .

LENAERTS, Koen - Fundamental rights to be included in a Community Catalogue, in European Law Review, 1991 (Vol. 16; n. ${ }^{\circ}$ 5), pp. 367-390.

Fundamental rights in the European Union, in European Law Review, 2000 (Vol. 25; n. ${ }^{\circ}$ ), pp. 570-600.

LENAERTS, Koen; e CAMBIEN, Nathan - Regions and the European Court: Giving Shape to the Regional Dimension of the Member States, in European Law Review, 2010 (Vol. 35; n. ${ }^{\circ}$ 5), pp. 609-635.

LENAERTS, Koen; e DESOMER, Marlies - Towards a Hierarchy of Legal Acts in the European Union? Simplification of Legal Instruments and Procedures, in European Law Journal, 2005 (Vol. 11; n. ${ }^{\circ}$ 6), pp. 744-765.

MACHADO, Jónatas - Direito da União Europeia, Coimbra, 2010.

MARQUES, Francisco Paes - $O$ acesso dos particulares ao recurso de anulação após o Tratado de Lisboa: remendos a um fato fora de moda, in Cadernos O Direito, n. ${ }^{\circ}$, 2010, pp. 89-109.

MARTINS, Ana Maria Guerra - Curso de Direito Constitucional da União Europeia, Coimbra, 2004. 
MESQUITA, Maria José Rangel de - O Poder Sancionatório da União e das Comunidades Europeias sobre os Estados Membros, Coimbra, 2006.

O sistema jurisdicional após o Tratado de Lisboa, in AA. VV, O Tratado de Lisboa. Jornadas organizadas pelo Instituto de Ciências Jurídico-Políticas da Faculdade de Direito da Universidade de Lisboa, Coimbra, 2012, pp. 71-94.

MOREIRA, Vital - A tutela dos direitos fundamentais na União Europeia, in AA. VV, Carta de Direitos Fundamentais da União Europeia, Coimbra, 2001, pp. 75-82.

PORTO, Manuel Lopes; e ANASTÁCIO, Gonçalo (coordenação) - Tratado de Lisboa. Anotado e comentado, Coimbra, 2012.

PRETE, Luca; e SMULDERS, Ben - The Coming of Age of Infringement Proceedings, in Common Market Law Review, 2010 (Vol. 47; n. ${ }^{\circ}$ ), pp. 9-61.

PROENÇA, Carlos Carranho - Tutela jurisdicional efetiva no direito da União Europeia, Coimbra, 2016.

QUADROS, Fausto de - Direito da União Europeia, 3. ${ }^{\text {a }}$ edição, Coimbra, 2013.

SAURON, Jean-Luc - Comprendre le Traité de Lisbonne, Paris, 2008.

WITTE, Floris de - The European Judiciary after Lisbon, in Maastricht Journal of

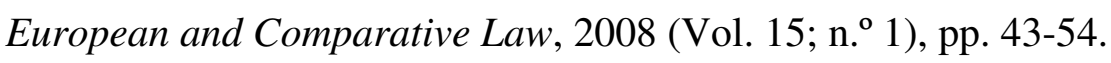

Artigo Recebido a 01 de junho de 2016 I Aceite a 09 de outubro de 2016 